\title{
Outcome of Fetoscopic Laser Coagulation in 61 Pregnancies with Twin-Twin Transfusion Syndrome in Viet Nam
}

\author{
Dinh Thi Hien Le ${ }^{1 *}$, Le Hoang ${ }^{1}$, Nguyen Huu Cong ${ }^{1}$, Pham Anh ${ }^{1}$, Nguyen Thi Hong Nhung ${ }^{1}$, Cao \\ Thị Thuý Hà ${ }^{1}$, Do Duy Anh ${ }^{2}$, Vo Kim Cat Tuyen ${ }^{3}$ and Le Tran Ngoan ${ }^{4,5}$ \\ ${ }^{1}$ Department of Obstetrics and Gynecology, Tam Anh Hospital, Hanoi city, Viet Nam \\ ${ }^{2}$ University of Manchester, UK
}

${ }^{3}$ Department of Obstetrics and Gynecology, International University of Health and Welfare, Japan

${ }^{4}$ Institute of Research and Development, Duy Tan University, Da Nang 550000, Viet Nam

${ }^{5}$ Department of Public Health, International University of Health and Welfare, Japan

*Corresponding author: Dinh Thi Hien Le, Tam Anh Hospital, Hanoi city, Viet Nam

ORCID: Ngoan Tran Le: 0000-0001-7862-492X

\section{ARTICLE INFO \\ Received: 业 November 26, 2021 \\ Published: December 03, 2021 \\ Citation: Dinh Thi Hien Le, Le Hoang, Nguyen Huu Cong, Pham Anh, Nguyen Thi Hong Nhung, et al., Outcome of Fetoscop- ic Laser Coagulation in 61 Pregnancies with Twin-Twin Transfusion Syndrome in Viet Nam. Biomed J Sci \& Tech Res 40(3)- 2021. BJSTR. MS.ID.006442.}

Keywords: Twin-Twin Transfusion Syndrome; Fetoscopic; Laser Coagulation; Monochorionic; Vietnam

\section{ABSTRACT}

Objectives: To examine the outcome of laser coagulation therapy in 61 pregnancies having twin-twin transfusion syndrome and other related factors in Viet Nam during 2018-2019.

Methods: In this prospective study, we included 61 pregnancies between 15 and 26 weeks of gestation having twin-twin transfusion syndrome (TTTS). All pregnancies were categorized with TTTS stage II or higher (Quintero classification) by ultrasound. Laser coagulation was performed by fetoscopic surgery. The last follow-up of the outcome of positive results was for 7 days after delivery. T-test and odds ratio and $95 \%$ confidence was estimated.

Results: All 61 pregnant women were healthy by the last follow-up time and 37 of them $(60.7 \%)$ having live births, of which six cases gave the single birth of the donor fetus, eleven cases gave the single birth of the recipient fetus, and 20 cases had successful birth of both twins. Newborn survived for 7 days was 57 (46.7\% of 122 gestation). There were not significant differences in birth weight between 6 single donor babies and 11 single recipient babies (mean 1,858.3g versus mean 1,954.5g, respectively), but significant differences in birth weight between blood donor and receiver in 20 cases of survived twins (mean 1,410.0g versus mean $1,782.5 \mathrm{~g}$, respectively).

Conclusion: The present findings suggest that other unknown factors might be responsible to a significant imbalance of birth weight among 20 of survived twins that warrant further significant investigation.

\section{Introduction}

Given the increasing implementation of assisted reproductive technologies in the reproductive medicine, the incidence of twin pregnancies has been continuing to rise [1]. Thirty percent of twin gestations have monochorionic placentas which are susceptible to complications because of their unique placental architecture $[2,3]$. Twin-to-twin transfusion syndrome (TTTS) is one of the 
most severe complications of monochorionic twin pregnancies, accounting for $15 \%$ of twin pregnancies [3,4]. When transfusion syndrome occurs, the two fetuses share different portions of the same placenta and connect with each other through placental superficial vascular anastomoses [2], leading to the poor prognosis for both two pregnancies. Approximately $90 \%$ of twins acquired TTTS result in intrauterine demise of one or both fetus or perinatal death without any intervention [5]. About 50\% of surviving twins are likely to leave irreversible neurological sequelae such as brain white matter necrosis, ventricular hemorrhage, cerebral dilation, cerebral palsy, neurocognitive impairment, etc [6-8]. The donor twin experiences the reduction of circulatory volume, anemia, decreased diuresis, oligohydramnios, hypotrophy. Meanwhile the recipient twin is characterized by circulatory hypervolemia, cardiomegaly, heart failure, fetal edema. Consequently, twins are at high risk of intrauterine demise or irreversible nerve damage after birth.

Treatment for TTTS includes methods such as amniocentesis, opening the amniotic septum between the two fetuses, fetoscopic laser coagulation (FLC) of the blood vessels connecting the two fetuses, or clamping the umbilical cord. Until now, the FLC and umbilical cord clamp are the only solutions to solve the pathogenesis of the TTTS. FLC was firstly conducted by De Lia at al. in 1990 under laparotomy and general anesthesia [9]. Subsequently, FLC has been improved and implemented in TTTS treatment worldwide [10]. It is demonstrated to be a beneficial therapy over serial aminoreduction in numerous population-based study as well as randomized controlled trial $[4,10,11]$. FLC has been also presented to reduce the long-term neurocognitive impairment in twins $[12,13]$. In Vietnam, Tam Anh Hanoi General Hospital is currently the only hospital that can perform FLC. However, there is no any study discussing the outcome of FLC in TTTS in Vietnam. Therefore, we conducted this study to evaluate the safety and therapeutic efficacy of FLC and other related factors in the outcomes of TTTS.

\section{Methods}

This is a prospective analysis study of pregnancies diagnosed with TTTS at the 16-26 week of gestation treated by FLC at Tam Anh Ha Noi General hospital, Vietnam. We included 61 consecutive pregnancies with moderate to severe mid trimester TTTS treated in our hospital of FLC between August 2018 and August 2019. This study protocol was approved by the Ethical Committee of Tam Anh Ha Noi General hospital on 1 August 1998. During the research period, all participants having TTTS confirmed by ultrasound and classified as the stage of II-IV (Quintero criteria) were extensively explained detailed risks and benefits of FLC. We only included participants accepting conducting the FLC and signing informed consent [14] [Box 1].
Box 1: Quintero's staging.

\begin{tabular}{|c|c|}
\hline Stage & Characteristics \\
\hline I & $\begin{array}{c}\text { Oligohydramnios in the donor sac and polyhydramnios in the } \\
\text { recipient sac. }\end{array}$ \\
\hline II & Absence of urine in the bladder of the donor fetus. \\
\hline III & Abnormal blood flow on Doppler. \\
\hline IV & Fetal hydrops. \\
\hline V & Fetal death. \\
\hline
\end{tabular}

All procedures were performed under local anesthesia and ultrasound guidance. Firstly, the physician identified the position of fetoscope which is the most feasible position to approach the boundary line between the 2 amniotic chambers on the placenta surface from the amniotic fluid of the recipient fetus (Figure 1). In detail, this position has to allow the fetoscope parallel with the vertical axis of the donor fetus. Moreover, the attach positions of umbilical cords to placentas have to be observed clearly so that the conjunctive vessel will be detected more easily. Later then, the fetoscope $\left(0^{\circ}\right.$ telescope, STORTZ) was introduced into the amniotic cavity of the recipient fetus and all the detected conjunctive vessels were coagulated along the whole vascular equator with a 0.4-0.6 $\mathrm{mm}$ fiber and laser system (20-40 watt of laser diot or laser YAGYttrium luminum Garnet).

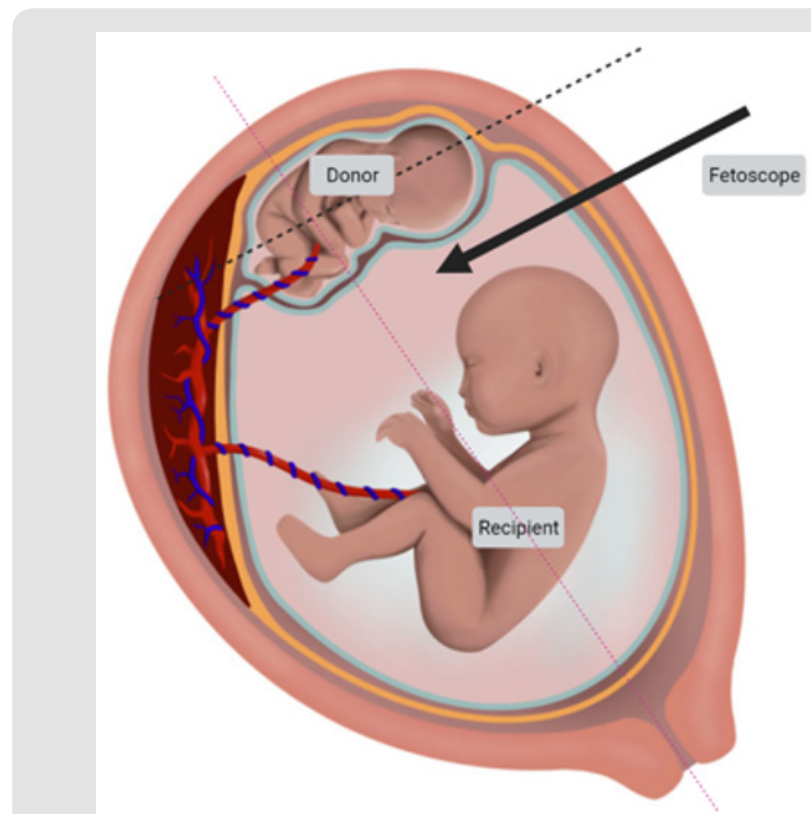

Figure 1: The most feasible position of fetoscope.

The primary outcome was survival rate after 2 weeks of surgery and the live birth rate of one or both two fetuses. We also identified gestational age at delivery, the birth weight of neonate, the APGAR score and the weight of neonates seven day after birth as the secondary outcome variables. Gestational age in weeks was 
calculated based on the mother's registration of her experienced due date. We divided gestation age at birth into very preterm (2831 weeks), moderate preterm (32-33 weeks), late preterm (34-36 weeks), early preterm (37-38 weeks), and full term (39-41 weeks). There was no post-term infants in the present prospective study. The birthplace at the Tam Anh hospital was only 21 pregnant women the remaining 40 pregnant women at the other 15 health facilities located in 14 provinces/cities nationwide.

Continuous variables are reported as mean and standard deviation (SD), categorical variables as absolute numbers and percentages. The differences in weight (percentage, \%) was calculated by the following formulation ((weight of blood receiverweight of blood donor) $* 100 /$ weight of blood receiver)) at the intervention time and the giving birth time, the end of gestation. Two-sided $\mathrm{p}<.05$ were considered as significant using a t-test and odds ratio and 95\% confidence interval. All statistical analyses were conducted with STATA Version 10.0.

\section{Results}

We recruited successfully 61 pregnant aged from 20 to 39, of which over 50\% aged 25-29. Among them, 37 (60.7\%) cases have reported having the first pregnancy, 17 (27.9\%) cases having second pregnancy; 47 cases have no history of abortion and remaining 14 cases reported having abortion at least one time; 24 women have alive children and 37 other women with the first pregnancy. There was 52 women (85.2\%) having history of caesarean section; 57 women (93.4\%) have natural conception. $40.1 \%$ of case had anterior placenta, whereas $59.9 \%$ ones had posterior placenta. In included pregnancies, there were 26 cases having velamentous cord insertion. According to the Quintero staging classification, there was 19,27 , and 15 of pregnancies categorized to be stage II, III, and IV, respectively (Table 1).

Table 1: Characteristics of study population.

\begin{tabular}{|c|c|c|c|c|c|c|}
\hline \multirow[b]{2}{*}{ Variables } & \multicolumn{2}{|c|}{ Not alive } & \multicolumn{2}{|c|}{ Alive } & \multicolumn{2}{|c|}{ Total } \\
\hline & Number & $\%$ & Number & $\%$ & Number & $\%$ \\
\hline \multicolumn{7}{|c|}{ Age of mother at the baseline } \\
\hline $20-24$ & 5 & 20.8 & 3 & 8.1 & 8 & 13.1 \\
\hline $25-29$ & 12 & 50.0 & 20 & 54.1 & 32 & 52.5 \\
\hline $30-34$ & 3 & 12.5 & 10 & 27.0 & 13 & 21.3 \\
\hline $35-39$ & 4 & 16.7 & 4 & 10.8 & 8 & 13.1 \\
\hline Total & 24 & 100 & 37 & 100 & 61 & 100 \\
\hline \multicolumn{7}{|c|}{ Pregnancy history } \\
\hline First & 12 & 50 & 25 & 67.6 & 37 & 60.7 \\
\hline Second & 9 & 37.5 & 8 & 21.6 & 17 & 27.9 \\
\hline Third or more & 3 & 12.5 & 4 & 10.8 & 7 & 11.5 \\
\hline Total & 24 & 100 & 37 & 100 & 61 & 100 \\
\hline \multicolumn{7}{|c|}{ Abortion history } \\
\hline No & 18 & 75 & 29 & 78.4 & 47 & 77 \\
\hline One & 3 & 12.5 & 6 & 16.2 & 9 & 14.8 \\
\hline Twice & 3 & 12.5 & 2 & 5.4 & 5 & 8.2 \\
\hline Total & 24 & 100 & 37 & 100 & 61 & 100 \\
\hline \multicolumn{7}{|c|}{ Alive children } \\
\hline Expecting & 12 & 50 & 25 & 67.6 & 37 & 60.7 \\
\hline 1 & 9 & 37.5 & 7 & 18.9 & 16 & 26.2 \\
\hline 2 & 2 & 8.3 & 5 & 13.5 & 7 & 11.5 \\
\hline 3 & 1 & 4.2 & 0 & 0 & 1 & 1.6 \\
\hline Total & 24 & 100 & 37 & 100 & 61 & 100 \\
\hline \multicolumn{7}{|c|}{ A history of operated delivery } \\
\hline Never & 21 & 87.5 & 31 & 83.8 & 52 & 85.2 \\
\hline Ever & 3 & 12.5 & 6 & 16.2 & 9 & 14.8 \\
\hline Total & 24 & 100 & 37 & 100 & 61 & 100 \\
\hline
\end{tabular}




\begin{tabular}{|c|c|c|c|c|c|c|}
\hline \multicolumn{7}{|c|}{ Conception } \\
\hline Nature & 23 & 95.8 & 34 & 91.9 & 57 & 93.4 \\
\hline IVF & 1 & 4.2 & 3 & 8.1 & 4 & 6.6 \\
\hline Total & 24 & 100 & 37 & 100 & 61 & 100 \\
\hline \multicolumn{7}{|c|}{ Quintero categorized } \\
\hline 2 & 9 & 37.5 & 10 & 27.0 & 19 & 31.1 \\
\hline 3 & 10 & 41.7 & 17 & 45.9 & 27 & 44.3 \\
\hline 4 & 5 & 20.8 & 10 & 27 & 15 & 24.6 \\
\hline Total & 24 & 100 & 37 & 100 & 61 & 100 \\
\hline \multicolumn{7}{|c|}{ The umbilical cord is attached to the membrane } \\
\hline No & 15 & 62.5 & 20 & 54.1 & 35 & 57.4 \\
\hline Yes & 9 & 37.5 & 17 & 45.9 & 26 & 42.6 \\
\hline Total & 24 & 100 & 37 & 100 & 61 & 100 \\
\hline \multicolumn{7}{|c|}{ Place of placenta } \\
\hline Front & 8 & 33.3 & 17 & 45.9 & 25 & 41.0 \\
\hline Back & 16 & 66.7 & 20 & 54.1 & 36 & 59.0 \\
\hline Total & 24 & 100 & 37 & 100 & 61 & 100 \\
\hline
\end{tabular}

Cervix length (mm) was 0-24 (eight cases), 25-29 (11 cases), 30-34 (21 cases), and 35-44 (21 cases). The difference (percentage) in weight $(\mathrm{g})$ between two gestations was $1.33 \%-20 \%$ (12 cases), $20.1 \%-40 \%$ (32 cases), and 40.1\%-62.23\% (17 cases). The age at FLC (in week) was 16-20 (27 cases), 21-23 (24 cases), and 24-26 (10 cases). The number coagulated vascular anastomoses was 2-9 places in 34 cases and 10-23 places in 25 cases (Table
2). The estimated average (mean $+/$ - standard deviation (SD)) of surgery time (minutes) was $35.3+/-11.1$; of the volume (ml) of drained amniotic fluid was 1,210.7+/-817.6; of the percent (\%) of differences between two fetal in weight was 30.9+/-13.6. At the intervention time, the estimated weight (g) of donor was significantly lower $(280.5 \mathrm{~g}+/-140.9 \mathrm{~g})$ than recipient $(415.0 \mathrm{~g}+/$ 204.2g), (Appendix Table 1).

Table 2: Clinical Features when performed fetoscopic laser coagulation.

\begin{tabular}{|c|c|c|c|c|c|c|}
\hline \multirow[b]{2}{*}{ Variables } & \multicolumn{2}{|c|}{ Not alive } & \multicolumn{2}{|c|}{ Alive } & \multicolumn{2}{|c|}{ Total } \\
\hline & Number & $\%$ & Number & $\%$ & Number & $\%$ \\
\hline \multicolumn{7}{|c|}{ Number of Laser therapy places } \\
\hline 2-9 places & 14 & 58.3 & 20 & 54.1 & 34 & 55.7 \\
\hline $10-23$ places & 9 & 37.5 & 16 & 43.2 & 25 & 41.0 \\
\hline Total & 23 & 95.8 & 36 & 97.3 & 59 & 96.7 \\
\hline \multicolumn{7}{|c|}{ Age at fetoscopic laser coagulation (week) } \\
\hline $16-20$ & 11 & 45.8 & 16 & 43.2 & 27 & 44.3 \\
\hline $21-23$ & 10 & 41.7 & 14 & 37.8 & 24 & 39.3 \\
\hline $24-26$ & 3 & 12.5 & 7 & 18.9 & 10 & 16.4 \\
\hline Total & 24 & 100 & 37 & 100 & 61 & 100 \\
\hline \multicolumn{7}{|c|}{ Per cent differences between two fetus in weight } \\
\hline $1.33 \%-20 \%$ & 5 & 20.8 & 7 & 18.9 & 12 & 19.7 \\
\hline $20.1 \%-40 \%$ & 16 & 66.7 & 16 & 43.2 & 32 & 52.5 \\
\hline $40.1 \%-62.23 \%$ & 3 & 12.5 & 14 & 37.8 & 17 & 27.9 \\
\hline Total & 24 & 100 & 37 & 100 & 61 & 100 \\
\hline \multicolumn{7}{|c|}{ Cervix length (mm) } \\
\hline $0-24$ & 3 & 12.5 & 5 & 13.5 & 8 & 13.1 \\
\hline $25-29$ & 4 & 16.7 & 7 & 18.9 & 11 & 18.0 \\
\hline $30-34$ & 11 & 45.8 & 10 & 27.0 & 21 & 34.4 \\
\hline $35-44$ & 6 & 25.0 & 15 & 40.5 & 21 & 34.4 \\
\hline Total & 24 & 100 & 37 & 100 & 61 & 100 \\
\hline
\end{tabular}


Appendix Table 1: Estimated indicators of twin-twin transfusion syndrome when treatment was performed.

\begin{tabular}{|c|c|c|c|c|c|c|}
\hline Variable & $\mathbf{n}$ & Mean & S.D. & Min & Median & Max \\
\hline Fetal age (in week) & 61 & 21.0 & 2.6 & 16.0 & 21.0 & 26.0 \\
\hline Weight of donor $(\mathrm{g})^{*}$ & 61 & 280.5 & 140.9 & 100 & 253.0 & 857.0 \\
\hline Weight of recipient $(\mathrm{g})^{*}$ & 61 & 415.0 & 204.2 & 133.0 & 378.0 & 1109.0 \\
\hline Differences (\%) between two fetal in weight & 61 & 30.9 & 13.6 & 1.3 & 29.2 & 62.2 \\
\hline Surgery time (minutes) & 61 & 35.3 & 11.1 & 15.0 & 32.0 & 60.0 \\
\hline The amount of amniotic fluid sucked out (ml) & 61 & 1210.7 & 817.6 & 200 & 1000 & 3200.0 \\
\hline Time in utero (in week) after treatment & 61 & 7.9 & 6.2 & 0 & 7 & 20 \\
\hline
\end{tabular}

Among 61 women, 15 cases were miscarriage after the intervention within 14 days after performed FLC, remaining 46 cases being followed up. Nine cases reported having neonatal mortality before or after delivery. There were 37 cases having babies survived for 7 days, at the last study follow-up, Figure 2. Among 37 cases having successful live birth, Quintero II, III, and IV was 10 cases, 17 , and 10 , respectively. The proportion of participants who have no survivors was gradually decreased by increased Quintero staging, 47.4\% (9/19), 37.0\% (10/27), and 33.3\% (5/15) for the Quintero II, III, and IV, respectively, non-statistically significant, $\mathrm{p}=0.394$. The gestation age (in weeks) at delivery was full term of 39-41 (3 cases), earlier preterm of 37-38 (4 cases), late preterm of 34-36 ( 9 cases), moderate preterm of 32-33 (8) and severe preterm of 28-31 (13 cases), Table 3.

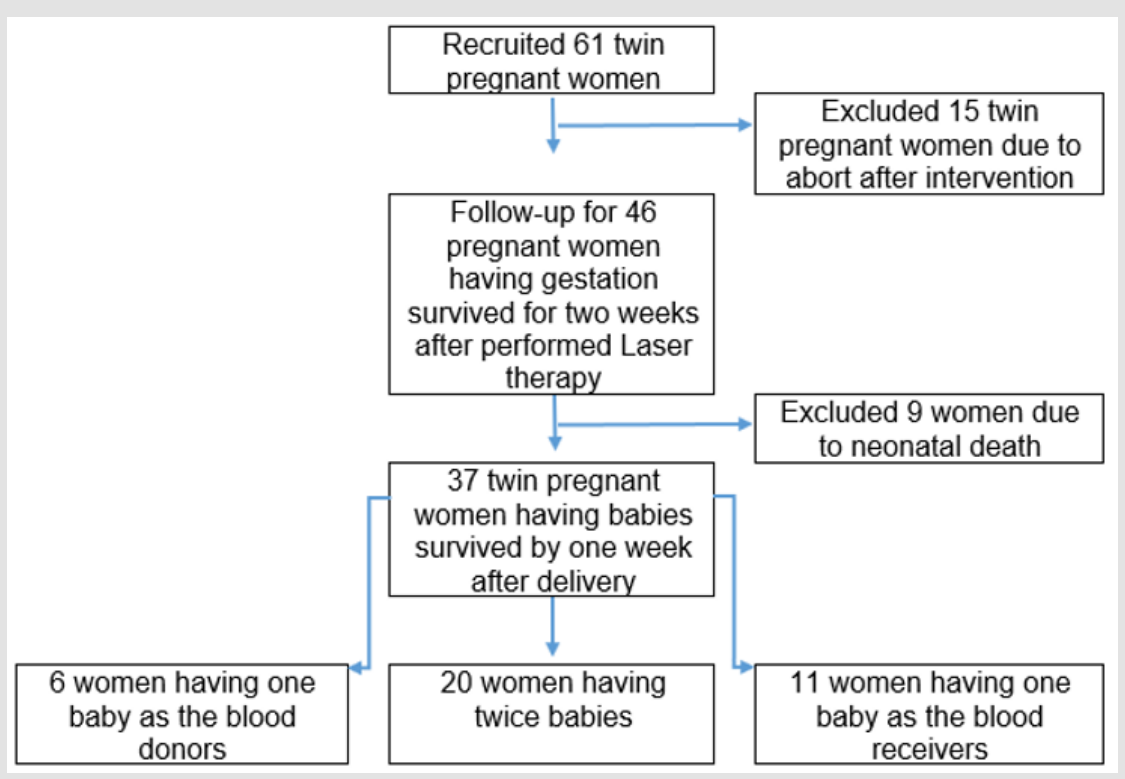

Figure 2: Flow-chart of recruited 61 twin pregnant women for treatment and the outcome.

Table 3: Distribution of newborn survived by 7 days after delivery by age of gestation.

\begin{tabular}{|c|c|c|c|c|c|c|c|}
\hline \multirow[b]{2}{*}{$\begin{array}{l}\text { Age at delivery } \\
\text { (week) }\end{array}$} & \multicolumn{3}{|c|}{ Quintero stage } & \multicolumn{3}{|c|}{ Status of twin-twin transfusion } & \multirow[b]{2}{*}{ Total } \\
\hline & II & III & IV & Twice & Receiver & Donor & \\
\hline $28-31$ & 3 & 8 & 2 & 6 & 5 & 2 & 13 \\
\hline $32-33$ & 0 & 3 & 5 & 5 & 2 & 1 & 8 \\
\hline $34-36$ & 3 & 4 & 2 & 6 & 2 & 1 & 9 \\
\hline $37-38$ & 1 & 2 & 1 & 3 & 1 & 0 & 4 \\
\hline $39-41$ & 3 & 0 & 0 & 0 & 1 & 2 & 3 \\
\hline Total & 10 & 17 & 10 & 20 & 11 & 6 & 37 \\
\hline
\end{tabular}


All 61 pregnant were healthy by the last follow-up time and 37 of them (60.7\%) having at least one liveborn neonate, of which six cases gave the single birth of the donor fetus, eleven cases gave the single birth of the recipient fetus, and 20 cases had successful birth of both twins. Newborn survived for 7 days was 57 (46.7\% of 122 gestation). There were not significant differences in birth weight between 6 single survived donors (mean 1,858.3g) and 11 single survived recipients (mean 1,954.5g), but significant differences in birth weight, among 20 survived twins, between donor twin (mean 1,410.0g) and recipient twin (mean 1,782.5g) in 20 cases of twins' delivery, Table 4 . The average weight ( $\mathrm{g}$ ) of the neonate was significantly lower in both the group of the gestation donors $(1,918.8 \mathrm{~g}$ versus $1,333.3 \mathrm{~g}, \mathrm{p}=0.012)$ and recipients $(2,260.0 \mathrm{~g}$ versus $1,763.5 \mathrm{~g}, \mathrm{p}=0.041$ ) when compared the categorized Quintero II to the categorized Quintero III-IV, Table 5.

Table 4: Weight of babies survived for 7 days in twin and single birth.

\begin{tabular}{|c|c|c|c|c|c|}
\hline & $\mathbf{n}$ & Mean & $\begin{array}{c}\text { Low } 95 \% \text { confidence } \\
\text { interval }\end{array}$ & $\begin{array}{c}\text { High } 95 \% \text { confidence } \\
\text { interval }\end{array}$ & $p$ for $t$ test \\
\hline \multicolumn{6}{|c|}{ Babies survived 7 days, two babies survived } \\
\hline Weight of donor (g) & 20 & 1410 & 1179.8 & 1640.2 & \\
\hline Weight of recipient (g) & 20 & 1782.5 & 1577.2 & 1987.8 & \\
\hline Differences (g) & 20 & -372.5 & -483.9 & -261 & 0.0000 \\
\hline \multicolumn{6}{|c|}{ Babies survived 7 days; one baby survived } \\
\hline Weight of donor (g) & 6 & 1858.3 & 895.1 & 2821.5 & \\
\hline Weight of recipient (g) & 11 & 1954.5 & 1419.3 & 2489.8 & \\
\hline Differences (g) & & -96.2 & -1003.8 & 811.4 & 0.4121 \\
\hline
\end{tabular}

Table 5: Weight of babies survived for 7 days by Quintero status.

\begin{tabular}{|c|c|c|c|c|c|}
\hline & $\mathbf{n}$ & Mean & $\begin{array}{c}\text { Low } 95 \% \text { confidence } \\
\text { interval }\end{array}$ & $\begin{array}{c}\text { High } 95 \% \text { confidence } \\
\text { interval }\end{array}$ & $p$ for $t$ test \\
\hline \multicolumn{6}{|c|}{ Weight of twin-twin blood donor by Quintero (g) } \\
\hline Quintero 2 & 8 & 1918.8 & 1269.7 & 2567.8 & \\
\hline Quintero 3-4 & 18 & 1333.3 & 1103.9 & 1562.8 & \\
\hline Differences & & 585.4 & 84.2 & 1086.6 & 0.012 \\
\hline \multicolumn{6}{|c|}{ Weight of twin-twin blood receiver by Quintero (g) } \\
\hline Quintero 2 & 5 & 2260 & 1161.3 & 3358.7 & \\
\hline Quintero 3-4 & 26 & 1763.5 & 1564.8 & 1962.1 & \\
\hline Differences & & 496.5 & -65.4 & 1058.5 & 0.0406 \\
\hline
\end{tabular}

When compared the indicators of the first ten performed cases to the last-ten cases, from the first to the last 61 participants consecutively recruited, the average surgery time was longer (41.4 versus 33.0 minutes) but the average number of coagulated vascular anastomoses vascular anastomoses was lower (6.3 versus 10.7). Among 20 surviving twins, the estimated differences (in percentage) in weight between donor and receiver gestations have continuously getting worse and increased in two cases, from $25.09 \%$ and $6.83 \%$ (at the treated time) to $43.75 \%$ and $21.74 \%$ (at the end of gestation), respectively. This difference in weight between donors and recipients has decreased in the remaining 18 cases.

\section{Discussion}

The successful FLC in our study was over $60 \%$ after seven days of birth with severe TTTS. The performed intervention was the first time successfully treated in Viet Nam and the achievements and main findings are significantly contributing to the develop the treatment technique of FLC for further better managements of TTTS in Viet Nam and at low- and medium economy countries. The proportion of Quintero stage IV in our study population was two time higher than the previous four studies combined $(24.6 \%$ (15/61) versus $12.3 \%$ (46/373)) [15-18], indicating big challenges to manage maternal and neonatal health in the present project. The higher proportion of the late stage of Quintero might be due to lack of established health facilities and trained physicians in the rural province in managing TTTS in the country. Therefore, the pregnant came to our hospital at the advanced stage of TTTS. Moreover, due to limited participants' resources and poor quality of transportation from other regions in the South and Central areas to the Hanoi city, only one third (21/61) participants have completed the recommended monitoring and following-up at our hospital 
that might cause a poor outcome of the present pilot intervention project. Therefore, social-determinant factors of maternal and child health were possibly related to the present intervention study.

The average age at the intervention time (week) in the present study was similarly to the other five previous studies [15-18], from 20 to 22 week. The estimated average surgery time in the present study (35 minutes) was longer than the other recent studies in Germany and France (27-29 minutes) [18,19]. Due to local limited quality of disinfection, some pregnant women were suffering from infection after completed intervention (2/61) resulting the premature ended of the gestation. This unwanted outcome was not seen in the other studies [20]. The average gestation age of newborn of 37 cases in the present study was approximately 4 weeks lower when compared to the previous 953 cases of nine studies combined (29 versus 33 weeks) [15,16,20-26]. After the intervention, these pregnant often came back to follow their pregnancies at the local hospitals at disadvantage areas that might be related to the shorter period of gestation age. The deficiency of well-trained physicians in managing of TTTS could contribute to the high rate of preterm birth in our study. Furthermore, as in the low economic status, the hard labor, the malnutrition in these pregnant could be also the explanation for this. The overall survival of at least one surviving gestation in the present study $(60.7 \%)$ was lower than previous four studies (69.2\%-84.0\%) [11,21,27-29].

Because there was not significant difference in weight $(\mathrm{g})$ between single surviving donors and single surviving recipients but it was observed among 20 surviving twins, the possible explanation is that the nature of limited amount of blood due to unknown related factors in the donors or the velamentous cord insertion involvement. Fifteen participants have no survivor (all had miscarriage within 2 weeks of treatment) and most of them among the first half time of recruited participants due to our limited experiences. The other 9 cases had neonatal death might be due to poor taking care by other local health facilities outside of our hospital in Hanoi city. In our study, the mean estimated surgery time in the first 10 cases is shorter than the last 10 cases. After some first cases, our team gradually got more experience and spent shorter time to find the vascular anastomoses positions and do the coagulation. Treatment technique in TTTS would be transferred from the established health facilities of developed countries to the other in the low- and middle economy countries and this work would be coordinated by an international association and institution in taking care better maternal and child health. We assume that there is an estimated $3.4 \%$ of pregnancy is twin, of which about 33\% is monochorionic; about $66 \%$ of monochorionic has the blood vessels connecting the two fetuses and about 15\% of them developing TTTS [30], among about 140 million pregnancy in 2020 worldwide, there was about 155,509 TTTS globally.
In order to improve maternal and child health, global project to manage TTTS is highly needed. With about million newborn per year, Viet Nam will have about 1,111 pregnancy that will be suffering from TTTS and the findings of the present project is timely and that will contribute greatly to manage TTTS in the country. The present study certainly has limitations including a lack of followup for about two-third of participants due to social-economy difficulties, limited local health facilities. Another limitation is the lack of neurodevelopment follow-up of delivered babies. In spite of these limitations, during 13 months running of the project, we just managed for only about $5.5 \%$ of the estimated 1,111 pregnancy with severe TTTS and the work would be improved for further better management and outcome of TTTS in Viet Nam in particular and in other low- and median economy countries.

\section{Acknowledgement}

We deeply appreciate study participants and their family members with their cooperation in taking care maternal and child health to manage TTTS in the present study.

\section{Conflict of Interest}

There are no conflicts to disclose.

\section{References}

1. Martin JA, Hamilton BE, Osterman MJK, Driscoll AK (2019) Births: Final Data for 2018. Natl Vital Stat Rep 68(13): 1-47.

2. Shanahan MA, Bebbington MW (2020) Placental Anatomy and Function in Twin Gestations. Obstet Gynecol Clin North Am 47(1): 99-116.

3. Benoit RM, Baschat AA (2014) Twin-to-twin transfusion syndrome: prenatal diagnosis and treatment. Am J Perinatol 31(7): 583-594.

4. Chalouhi GE, Essaoui M, Stirnemann J, Quibel T, Deloison B, et al. (2011) Laser therapy for twin-to-twin transfusion syndrome (TTTS). Prenat Diagn 31(7): 637-646.

5. Robyr R, Lewi L, Salomon LJ, Yamamoto M, Bernard JP, et al. (2006) Prevalence and management of late fetal complications following successful selective laser coagulation of chorionic plate anastomoses in twin-to-twin transfusion syndrome. Am J Obstet Gynecol 194(3): 796803.

6. Haverkamp F, Lex C, Hanisch C, Fahnenstich H, Zerres K (2001) Neurodevelopmental risks in twin-to-twin transfusion syndrome: preliminary findings. Eur J Paediatr Neurol 5(1): 21-27.

7. Van Klink JM, Koopman HM, Van Zwet EW, Oepkes D, Walther F, et al. (2013) Cerebral injury and neurodevelopmental impairment after amnioreduction versus laser surgery in twin-twin transfusion syndrome: a systematic review and meta-analysis. Fetal Diagn Ther 33(2): 81-89.

8. Van Klink JM, Koopman HM, Rijken M, Middeldorp JM, Oepkes D, et al. (2016) Long-Term Neurodevelopmental Outcome in Survivors of Twinto-Twin Transfusion Syndrome. Twin Res Hum Genet 19(3): 255-261.

9. De Lia JE, Cruikshank DP, Keye WR Jr (1990) Fetoscopic neodymium:YAG laser occlusion of placental vessels in severe twin-twin transfusion syndrome. Obstet Gynecol 75(6): 1046-1053.

10. Akkermans J, Peeters SHP, Klumper FJ, Lopriore E, Middeldorp JM, et al. (2015) Twenty-Five Years of Fetoscopic Laser Coagulation in Twin-Twin Transfusion Syndrome: A Systematic Review. Fetal Diagn Ther 38(4): 241-253. 
11. Senat MV, Deprest J, Boulvain M, Paupe A, Winer N, et al. (2004) Endoscopic laser surgery versus serial amnioreduction for severe twinto-twin transfusion syndrome. N Engl J Med 351(2): 136-144.

12. Banek CS, Hecher K, Hackeloer BJ, Bartmann P (2003) Long-term neurodevelopmental outcome after intrauterine laser treatment for severe twin-twin transfusion syndrome. Am J Obstet Gynecol 188(4): 876-880.

13. Salomon LJ, Ortqvist L, Aegerter P, Bussieres L, Staracci S, et al. (2010) Long-term developmental follow-up of infants who participated in a randomized clinical trial of amniocentesis vs laser photocoagulation for the treatment of twin-to-twin transfusion syndrome. Am J Obstet Gynecol 203(5): 444.e1-7.

14. Quintero RA, Morales WJ, Allen MH, Bornick PW, Johnson PK, et al. (1999) Staging of twin-twin transfusion syndrome. J Perinatol 19/8 Pt 1): 550-555.

15. Middeldorp JM, Sueters M, Lopriore E, Klumper FJC M, Oepkes D, et al. (2007) Fetoscopic laser surgery in 100 pregnancies with severe twin-totwin transfusion syndrome in the Netherlands. Fetal Diagn Ther 22(3): 190-194.

16. Cincotta RB, Gray PH, Gardener G, Soong B, Yee Chan F (2009) Selective fetoscopic laser ablation in 100 consecutive pregnancies with severe twin-twin transfusion syndrome. Aust N Z J Obstet Gynaecol 49(1): 22 27.

17. Sago H, Hayashi S, Saito M, Hasegawa H, Kawamoto H, et al. (2010) The outcome and prognostic factors of twin-twin transfusion syndrome following fetoscopic laser surgery. Prenat Diagn 30(12-13): 1185-1191.

18. Weingertner AS, Kohler A, Mager C, Miry C, Viville B, et al. (2011) Fetoscopic laser coagulation in 100 consecutive monochorionic pregnancies with severe twin-to-twin transfusion syndrome. J Gynecol Obstet Biol Reprod (Paris) 40(5): 444-451.

19. Diehl W, Diemert A, Grasso D, Sehner S, Wegscheidar K, et al. (2017) Fetoscopic laser coagulation in 1020 pregnancies with twin-twin transfusion syndrome demonstrates improvement in double-twin survival rate. Ultrasound Obstet Gynecol 50(6): 728-735.

20. Swiatkowska-Freund M, Pankrac Z, Preis K (2012) Results of laser therapy in twin-to-twin transfusion syndrome: our experience. J Matern Fetal Neonatal Med 25(10): 1917-1920.

\section{ISSN: 2574-1241}

DOI: $10.26717 /$ BJSTR.2021.40.006442

Dinh Thi Hien Le. Biomed J Sci \& Tech Res

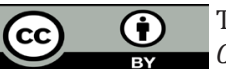

This work is licensed under Creative

Commons Attribution 4.0 License

Submission Link: https://biomedres.us/submit-manuscript.php
21. De Lia JE, Kuhlmann RS, Lopez KP (1999) Treating previable twin-twin transfusion syndrome with fetoscopic laser surgery: outcomes following the learning curve. J Perinat Med 27(1): 61-67.

22. Quintero RA, Comas C, Bornick PW, Allen MH, Kruger M (2000) Selective versus non-selective laser photocoagulation of placental vessels in twinto-twin transfusion syndrome. Ultrasound Obstet Gynecol 16(3): 230236.

23. Huber A, Diehl W, Bregenzer T, Hackeloer BJ, Hecher K (2006) Stagerelated outcome in twin-twin transfusion syndrome treated by fetoscopic laser coagulation. Obstet Gynecol 108(2): 333-337.

24. Quintero RA, lshii K, Chmait RH, Bornick PW, Allen MH, et al. (2007) Sequential selective laser photocoagulation of communicating vessels in twin-twin transfusion syndrome. J Matern Fetal Neonatal Med 20(10): 763-768.

25. Meriki N, Smoleniec J, Challis D, Welsh AW (2010) Immediate outcome of twin-twin transfusion syndrome following selective laser photocoagulation of communicating vessels at the NSW Fetal Therapy Centre. Aust N Z J Obstet Gynaecol 50(2): 112-119.

26. Chang YL, Chao AS, Chang SD, Hsieh PCC, Wang CN (2012) Short-term outcomes of fetoscopic laser surgery for severe twin-twin transfusion syndrome from Taiwan single center experience: demonstration of learning curve effect on the fetal outcomes. Taiwan J Obstet Gynecol 51(3): 350-353.

27. De Lia JE, Kuhlmann RS, Harstad TW, Cruikshank (1995) Fetoscopic laser ablation of placental vessels in severe previable twin-twin transfusion syndrome. Am J Obstet Gynecol 172(4 Pt 1): 1202-1208.

28. Ville Y, Hecher K, Gagnon A, Sebire N, Hyett J, et al. (1998) Endoscopic laser coagulation in the management of severe twin-to-twin transfusion syndrome. Br J Obstet Gynaecol 105(4): 446-453.

29. Stirnemann J, Djaafri F, Kim A, Mediouni I, Bussieres L, et al. (2018) Preterm premature rupture of membranes is a collateral effect of improvement in perinatal outcomes following fetoscopic coagulation of chorionic vessels for twin-twin transfusion syndrome: a retrospective observational study of 1092 cases. Bjog 125(9): 1154-1162.

30. Bamberg C, Hecher K (2019) Update on twin-to-twin transfusion syndrome. Best Pract Res Clin Obstet Gynaecol 58: 55-65.

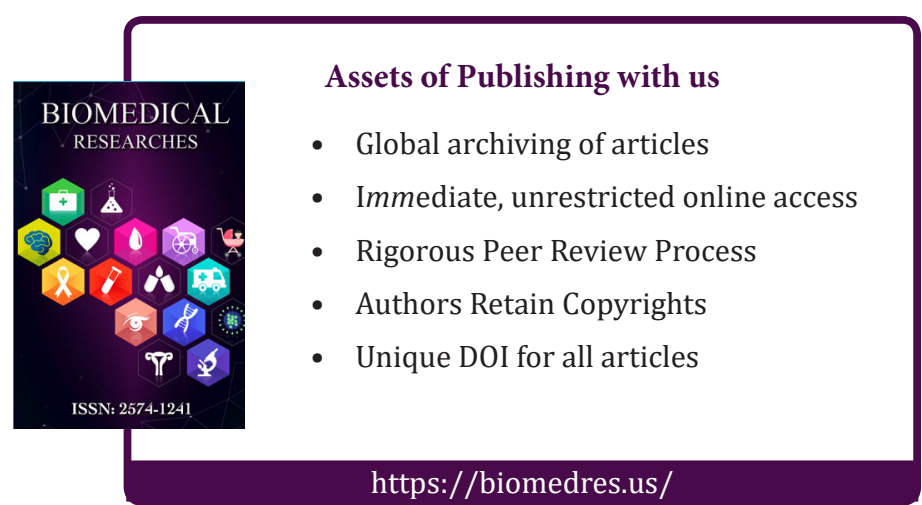

